\title{
Assessment of Patient Satisfaction Among Pregnant Patients in The Out-Patient Department of Obstetrics and Gynecology Section at Metropolitan Medical Center Manila
}

\author{
Herry Prabowo Krestiyanto Widjaja \\ Department Obstetrics and Gynecology Metropolitan Medical Center, Manila \\ Email: herry_pkw@yahoo..com
}

\begin{abstract}
Patient satisfaction reflects the quality of an institution's delivery of health care services. Patient satisfaction is a critical factor in improvement or complete recuperation to wellness because satisfied patients will mean better compliance with treatment or follow up. As reported in the 2017 Annual OPD census of the Department of Obstetrics and Gynecology, there were 2617 total patient consultations. The majority of these (2138 or $81.7 \%)$ were obstetrical cases. The average number of consultations per day (for Obstetrics and Gynecology patients combined) is 91. Therefore, the Out-Patient Clinic plays an important role in prenatal care, specifically preventing adverse maternal and neonatal morbidity and mortality. This study aimed to assess patient satisfaction among obstetrical patients in the Out-Patient Department of the Obstetrics and Gynecology Section at Metropolitan Medical Center from July 1, 2018, to July 31, 2018, and to see the relationship between a socio-demographic characteristic and the level of patient satisfaction. This study was a descriptive, cross-sectional study. Patient satisfaction was assessed as to physical facilities, the interaction between doctor and patient, the interaction between nurses and patient, and registration service. There were sixty-three subjects in this study. Sixty-three were satisfied with the inclusion criteria. The
\end{abstract}

validated questionnaire was the pretested questionnaire, $96 \%$ valid and reliable by Cronbach's analysis.

Statistical analysis was done, which showed that respondents were generally satisfied. There was a significant relationship association between socio-demographic characteristics and level of patient satisfaction with a p-value $<0.05$.

Keyword : Patient Satisfaction, Socio Demographic Characteristic

\section{INTRODUCTION}

Patient satisfaction is gaining attention because it reflects the quality of an institution's delivery of health care services. Patient satisfaction is not limited to medical or surgical services but also includes infrastructure, logistics, Medical staff to patient relationship as well as non-medical to patient relationship. The health care system as a whole to meet individual patient needs. Patient satisfaction is a critical factor in improvement or complete recuperation to wellness because satisfied patients will mean better compliance to treatment or follow up.

Metropolitan Medical Center, a tertiary hospital, aims to continually improve quality management system to the highest satisfaction of its clients. As reported in the 2017 Annual OPD census of the Department of Obstetrics and Gynecology, there were 2617 total patient 
consultations. Majority of these (2138 or $81.7 \%$ ) were obstetrical cases. The average number of consultations per day (for Obstetrics and Gynecology patients combined) is 9. ${ }^{1}$ Therefore, the Out-Patient Clinic plays an important role in prenatal care specifically the prevention of adverse maternal and neonatal morbidity and mortality.

This study aimed to assess patient satisfaction among obstetrical patients seen at the Out-Patient Department of Metropolitan Medical Center from July 1, 2018 to July 31, 2018, with the hope that the results and recommendation of the study will be useful in upgrading Out-Patient services to make it more effective, efficient, and satisfying to its clientele.

\section{METHODS}

This was a descriptive, cross sectional study which aims to determine the level of patient satisfaction and its significant relationships with socio-demographic characteristics of the sample population. The study was conducted at the Out-Patient Department of the Obstetrics and Gynecology Section at Metropolitan Medical Center from July 1, 2018 - July 31, 2018.

Sixty three (63) obstetrical patients who satisfied the inclusion/exclusion criteria were recruited by simple random sampling, to achieve $80 \%$ power and $95 \%$ confidence interval. To account for about $20 \%$ drop-out rate or non-response rate, a minimum of 60 obstetrics outpatients should have been enrolled in the study. ${ }^{7}$ The study population included 63 pregnant patients in the Out Patient Department, (both old and new charity patients) who came in for pre-natal checkup starting July 1, 2018 to July 31, 2018.

The study commenced with an interview of the subject in the Out-Patient Department, to determine if the inclusion criteria are met, to explain the purpose and the mechanics of the study and to secure an informed consent. Questionnaires were handed over to the subjects for them to fill up. The researcher was available to clarify and explain items as the need arises.
Ethical approval for the survey and data collection was sought from the Metropolitan Medical Center Ethics Committees. Ethics Committee approved the use of informed consent form that filled by respondent. Before interviewing, all respondents were briefed on the purpose of the survey and they were assured about the confidentiality of the information collected and their right to refuse to participate or withdraw at any time during the interview.

\section{RESULTS AND DISCUSSION}

There were sixty three (63) patients who participated in this study, sixty three (63) qualified. Most of the patients were single $(54 \%)$ and $75 \%$ of them were college graduates, but most of them were unemployed (54\%). Forty four percent (44\%) consulted for more than five times. Majority of them paid their expenses (ie registration fee, laboratory and diagnostic procedures like Ultrasound) from their own income (73\%). Most of our patients choose Metropolitan Medical Center because it has good services and highly recommended by family or relatives.

For the doctor's service, $19(30 \%)$ were very satisfied, $44(70 \%)$ were satisfied. As to Nurse's service, 32 (51\%) were very satisfied, $31(49 \%)$ were satisfied. $46 \%$ were satisfied with physical facilities, doctor's service, nurse's service, and with registration service and its relation with satisfied patient ratio is significant with a $\mathrm{P}$ Value $<0.05$.

The Metropolitan Medical Center is a tertiary private hospital. Majority of the patients seen at the Obstetrics and Gynecology Section of the Out Patient Department came in for prenatal check-up is from low-middle class socio-economic status. This is a window of opportunity to provide health education on the level of their understanding and stressed out the danger signs of pregnancy.

Obtaining patient's opinion about the services they receive during their prenatal check-up may serve as a tool for improving the quality of health services and may serve as a basis in the planning, implementation and monitoring of health care services. 
In this study, the subjects were found to be generally satisfied with the services they received at the Obstetrics and Gynecology Section of the Out Patient Department. This may not be reflective of the true feelings or satisfaction of the respondents because it is affected by several factors at the time of the study. Although the research has been explained thoroughly there was still a hesitation to answer the questionnaires honestly. Upon observation, during the process of answering the questionnaire, some respondents felt uncomfortable in describing their experiences and their opinion about the services they received. Some of the respondents were in a hurry filling up the questionnaire and did not read the contents carefully. This is because of their fear of telling their true observations about the service that may affect how they will be attended to during their prenatal check up.

Nevertheless, this study had shown the significant relationship between sociodemographic factors and level of patient satisfaction in the Obstetrics and Gynecology of the Out-Patient Department. Majority of our respondents belonged to low socioeconomic status (monthly income of less than 10,000). Respondents age 18-25 years and mostly single mothers. Mostly respondents college graduated, and unemployed, but were satisfied with the service. This study has shown most of them satisfied after 5th prenatal check up, it may be due to good service at Obstetrics and Gynecology Section of the Out Patient Department and short waiting hours.

Although most of our respondents paid their treatment, they were satisfied with our service. Most of the monthly family income of our respondents is less than PhP 10,000. Metropolitan Medical Center being a private hospital provides affordable health care for Out Patient Department.

The respondents had chosen MMC because it is accessible, good service and highly recommended commonly referred by family and relatives, which can be easily reached in $<15$ minutes using public transportation.
Most of our respondents came in between 7:00 - 10 AM to have their registration. The duration from the registration until consultation is about 2-4 hours. Upon observation, the bottle neck was noted to be at the registration area wherein retrieving patient's chart took times, due to the chart is not in place. No significant difference between respondents that request for appointment basis or not, but if with appointment basis that charts could be retrieved faster, thus avoiding delays and long waiting time. Despite these problems, most of our respondents agree to recommend Metropolitan Medical Center to other patients.

\section{CONCLUSION}

In summary, patient satisfaction provides a guide in improving health services. This study showed that there is significant correlation between socio-demographic and level of patient satisfaction. Most of our satisfied respondents are in age between 1825 years and single. Most of them college graduates were unemployed and with lowmiddle class socio-economic status, hence explaining why they choose a private hospital like Metropolitan Medical Center for its accessibility, affordability, and good service known to family and relatives. But only few respondent aware about MMC thru barangay, and no respondent aware about MMC from media.

With the positive result, Health care providers should not be complacent as this may not be the true reflection of the patient's feeling or assessment because of several factors affecting their answers at the time of the interview. They should instead, strive to look for the answers and accommodate the concerns of dissatisfied respondents, because they may reflect the true assessment where improvement can be implemented.

The hospital should do regular evaluation of patient satisfaction should be implemented and upgrading the OPD Medical Record Section to EMR (Electronic Medical Record) for faster and systematic retrieval of charts also interpersonal manner and communication 
skills should be improved. Cleanliness, comfort and quality care in the Out Patient Department should be maintain. The hospital should do collaboration with Barangay and do promotion thru social media or bulletin. Future studies may focus on in-depth interview with respondents. Qualitative research can be conducted together with quantitative research on patient satisfaction with the service.

\section{ACKNOWLEDGEMENTS}

The authors would like to acknowledge the support from Metropolitan Medical Center Ethics Committee, and all OutpatientDepartment of Obstetrics and Gynecology staff, for their support and encouragement while preparing the paper. Also, authors would like to thanks to Dr. Benjamin D. Cuenca as Chairman of Department of Obtetrics and Gynecology Metropolitan Medical Center and to Dr. Elizabeth Supelana, training officer of Department of Obtetrics and Gynecology Metropolitan Medical Center for their support for manuscript review. This research was not funded by any organization or company.

\section{REFERENCES}

1. Metropolitan Medical Center, Annual OPD Census 2017

2. Irfan, Raja et al. "Impact of Service Quality on Patient's Satisfaction using SERVQUAL: A comparison of Combined Military, Private and Government Hospitals of Pakistan." Journal of Basic and Applied Scientific Research, 2014.

3. Isha Patel et al. Patient satisfaction with obstetricians and gynecologists compared with other specialties: analysis of US self-reported survey data. Published 21 July 2011. Available from https://www.ncbi.nlm.nih.gov/pmc/article s/PMC3417920/\#b1-prom-2-021;

Internet; accessed on 17 March 2018.

4. Yeh,John and Nagel,.Eryn E. "Patient Satisfaction in Obstetrics and Gynecology:Individualized Patientcentered Communication".Clinical
Medicine Insights: Women's Health, 2010:3 23-32. Available from http://insights.sagepub.com/redirect_file. php?fileId $=3180 \&$ filename $=2336$ -

CMWH-Patient-Satisfaction-in-

Obstetrics-and-Gynecology:Individualized-Pati.pdf\&fileType=pdf; Internet; accessed on 24 March 2018.

5. Mao, Vadhana "Assesment of Patient Satisfaction in an Outpatient Dapartment of An Autonomous Hospital In Phnom Penh, Cambodia", Thesis Asia Pacific University, 2012

6. Ny Net, "Patient Satisfaction Towards Health Services at The Outpatient Department Clinic of Wangnumyen Community Hospital, Sakeo Province, Thailand, Thesis Mahidol University, 2007

7. V.A., Zeithaml, A. Parasuraman, \& Berry, L.L. Delivering Quality ServicesBalancing Customer Perceptions and Expectation. New York: The Free Press, 1990.

8. Alder, J. Christen, R., Zemp, E., Bitzer, J. Communication skills training in obstetrics and gynecology: whom should we train? A randomized controlled trial. Arch Gynecol Obstet.2007; 276: 605-12.

9. Shilling, V., Jenkins, V., Fallowfield, L. Factors affecting patient and clinician satisfaction with the clinical consultation: can communication skills training for clinicians improve satisfaction? PsychoOncol.2003; 12: 599-611.

10. A. Srivastava, B. I. Avan, P. Rajbangshi, and S. Bhattacharyya, "Determinants of woman's satisfaction with maternal health care: a review of literature from developing countries,"BMC Pregnancy and Childbirth,vol.15, no. 1, pp. 1-12, 2015.

11. Hotchkiss DR, Krasovec K, El-Idrissi MDZ, Eckert E, Karim AM. The role of user charges and structural attributes of quality on the use of maternal health services in Marocco. Int $J$ Health Plann Manag. 2005;20(2):113-135. doi: 10.1002/hpm.802. 
12. Nigenda G, Langer A, Kuchaisit C, Romero M, Rojas G, Al-Osimy M, et al. Women's opinions on antenatal care in developing countries: results of a study in Cuba, Thailand, Saudi Arabia and Argentina. BMC Public Health. 2003;3:17. doi:10.1186/1471-2458-3-17.

13. Ganasegeran K., Perianayagam W., Abdul Manaf R., Jadoo A., Ahmed S., Al-Dubai S.A.R. Patient satisfaction in Malaysia's busiest outpatient medical care. Sci. World J. 2015;2015:714754. doi: 10.1155/2015/714754.

14. Mohd A., Chakravarty A. Patient satisfaction with services of the outpatient department. Med. J. Armed Forces India. 2014;70:237-242. doi 10.1016/j.mjafi.2013.06.010.

15. Nabbuye-Sekandi J, Makumbi FE, Kasangaki A, Kizza IB, Tugumisirize J, Nshimye E, et al. Patient satisfaction with services in outpatient clinics at Mulago hospital, Uganda. Int $J$ Qual Health Care. 2011;23:516-523. doi: 10.1093/intqhc/mzr040.

16. Nwaeze II, Enabor OO, Oluwasola TA, Aimakhu CO. Perception and Satisfaction with Quality of Antenatal Care Services among Pregnant Women at the University College Hospital, Ibadan, Nigeria. Ann Ib Postgrad Med 2013;11(1):22-8.

17. Simkhada B, Teijlingen ER, Porter M, Simkhada P. Factors affecting the utilization of antenatal care in developing countries: Systematic review of the literature. J Adv Nurs 2008:61(3):244-60.

18. Victora C, Matijasevich A,Silveria $M$ et al..Socio-economic and ethnic group inequities in antenatal care quality in the public and private sector in Brazil. Health Policy Plan 2010;25:253-61.

19. Shabbir A., Malik S.A.. Measuring patients' healthcare service quality perceptions, satisfaction, and loyalty in public and private sector hospital in Pakistan. Int. J. Qual. Reliab. Manag. 2016;33:538-557. doi: 10.1108/IJQRM0602014-0074.

20. Sun J., Hu G., Ma J., et al. Consumer satisfaction with tertiary healthcare in China: Findings from the 2015 China National Patient Survey. Int. J. Qual. Health Care. 2017;29:213-221. doi: 10.1093/intqhe/mzw 160.

21. Boyer L, Francois P, Doutre E, et al. Perception and use of the results of patient satisfaction surveys by care providers in a French teaching hospital, Int J Qual Health Care, 2006, vol.18 (pg. 359-64). doi: 10.1093/intqhe/mzl029.

22. Hall JA, Dornan MC. Patient sociodemographic characteristics as predictors of satisfaction with medical care: meta-analysis. Soc Sci Med.1990;30(7):811-8.

23. Young GJ, Meterko M, Desai KR. Patient satisfaction with hospital care: effects of demographic and institutional characteristics. Med care. 2000;38(3):325-34

24. Saeed AA, Mohammed BA, Magzoub ME, et al. Satisfaction and correlates of patients' satisfaction with physicians' services in primary health care centers. Saudi Med J. 2001;22(3):262-7.

25. Bleich SN, Ozaltin E, Murray CJ. How does satisfaction with the health-care system relate to patient experience? Bull World Health Organ. 2009;87(4):271-8. 